\title{
Transanal endoscopic microsurgery
}

\begin{abstract}
Background: Transanal endoscopic microsurgery (TEM) presents a minimally invasive procedure for local removal of large adenomas a well as early carcinomas of the rectum. TEM of advanced rectal cancer remains a controversial issue although it has become a more attractive option because of the regular use of neoadjuvant therapy at several centers. TEM's availability and utilization a Caribbean medical community has been limited and remains a challenge.
\end{abstract}

Methods: This study was a retrospective review uses a prospectively maintained database of patients underwent TEM from 2004 to 2015. Age, gender, indications, operative time, tumor distance from the anal verge, tumor size, hospital stay, postoperative complications and local recurrence were included in a study.

Results: A total of 171 patients underwent TEM during a period of 11 years. Main indication of TEM was the presence of carcinoma: $85(49,7 \%)$. The median age of patients was 63years, median operative time was of 81,7minutes (20-240) and median specimen size was $3,4 \mathrm{~cm}$. Hospital stay was of 1,4 days and main postoperative complications were four bleeding, two dehiscence and two rectovaginal fistula. Two patients had local recurrences in the adenoma group $(3,6 \%)$ treated by TEM, and two in the $\mathrm{T} 1$ group $(5,8 \%)$ treated by laparoscopic surgery. There were no conversions to laparoscopic or conventional surgery.

Conclusion: In an advanced Caribbean medical community, TEM can be utilized for patient's safety with good adenoma control and oncologic outcomes. Propagate of advanced surgical technologies in a developing medical remains challenging but our experience supports the feasibility and potential of this approach.

Keywords: transanal endoscopic microsurgery, TEM, rectal cancer, rectal adenoma, technology in developing country
Volume 5 Issue 2 - 2017

\section{Javier Ernesto Barreras González}

Department of Laparoscopic and Endoscopic Surgery, Havana Medical University, Cuba

Correspondence: Javier Ernesto Barreras González MD PhD Department of Laparoscopic and Endoscopic Surgery, Nationa Center for Minimally Invasive Surgery, Párraga Street b/ San Mariano and Vista Alegre. La Víbora. 10 de Octubre, Havana, Cuba, Fax 537-649-0I5-0, Tel 537-649-533-3,

Email javier.barrera@infomed.sld.cu; javierdeu_3008@yahoo.es

Received: September 14, 2017 | Published: November 13,

\section{Introduction}

Delivery of healthcare in different economic models presents opportunities and challenges for the generations and populations. In the Caribbean nations, there is a wide disparity of level of healthcare provided both between countries and within individual countries. The Cuban medical system is very advanced in comparison to other countries (Caribbean region). In fact in the infant mortality rate or in the survival of the cancer colorectal, it is compared favorably with the western countries. However the introduction of advanced technology in this global environment is hampered by challenges with cost, equipment maintenance and supply chain issues. The benefits of these approaches however are equally advantageous for people of all countries, regardless of the country they were born and live in. A number of surgical techniques have been implemented to remove rectal tumors locally. Transanal endoscopic microsurgery (TEM) is a newly popular, minimally invasive technique for that purpose. In the 1983, Gerhard Buess introduced TEM. He developed the technique according to a fixed action plan, including experiments on animals, after which he progressed to clinical introduction. In addition, he set up training courses for interested surgeons to introduce the new technology safely. ${ }^{1-3}$ TEM is ideally performed in patients with benign large adenomas and low-risk superficial carcinomas of the rectum. It is a local excision technique, which enables the surgeon to perform a submucosal or full thickness excision with great precision. By using an operating rectoscope with a diameter of $4 \mathrm{~cm}$ and a length of 12 or $20 \mathrm{~cm}$ is used the most challenging aspect of transanal surgery, reaching the cephalad margins, is easily achieved. The scope has four work channels, a stereo optic vision channel, a light source, and an insufflations port to obtain a pneumorectum for maximum exposure. ${ }^{4,5}$ TEM has been shown to be superior to transanal excision (TAE) for benign and malignant rectal neoplasms. There is a significantly lower risk of fragmented of piecemeal excision, incomplete resection and consequently a lower recurrence rate.,6-8 TEM of more advanced rectal cancer remains a controversial issue. However TEM has recently become a more attractive option because of the regular use of neoadjuvant therapy at several centers. ${ }^{4,5,8-13}$ Still other indications have also been described: repair of high or supralevator fistulas, rectourethral fistulas and rectal prolapse, drainage of pelvic collections, impacted fecaloma and excision of extra rectal masses. ${ }^{5,14-16}$ The aim of this study is a report on the introduction of a national program of advanced surgical technology at the National Center for Minimally Invasive Surgery in Havana, Cuba.

\section{Materials and methods}

A retrospective review uses a prospectively maintained database of patients underwent TEM from April 2014 to December 2015 at the National Center for Minimally Invasive Surgery, Havana, Cuba. This is a tertiary referral university-affiliated center specializing in endoscopic and laparoscopic surgery. All the procedures were performed by the same surgical team (surgeon and nurse), which was trained by professor Gerhard Buess at the Training Center for Minimally Invasive Surgery (Eberhard-Karls-University. Tübingen). Informed consent was obtained from patients before performing the procedure. The study was approved by our Institution Ethical Committee. Inclusion criterion included a planned TEM for benign 
rectal diseases (adenomas, rectal prolapses, stenosis, granuloma, abscess, impacted fecaloma) and malignant rectal tumors (uT1 N0 low risk, uT2 N0 low risk with neoadjuvant therapy and uT3 N0 low risk and complete response after neoadjuvant therapy), specified tumor located within $8 \mathrm{~cm}$ from the anal verge and a tumor diameter of $3 \mathrm{~cm}$ or less. The surgery was performed 12 weeks after the completion of neoadjuvant therapy. The selection was restricted to fit patients (American Society of Anesthesiologists classification I-II-III). Exclusion criteria were circumferential tumors, uT1-2-3 N0 high risk, uT3 N0 with poor response after neoadjuvant therapy and rectal cancer over $3 \mathrm{~cm}$ of diameter. The parameters studied were age, gender, indications, operative time, location, tumor distance from the anal verge, tumor size, conversions, and length of hospital stay, postoperative complications, mortality and local recurrence. Operative time was defined as the time beginning with the introduction of the rectoscope until the completion of the last suture. Distance was defined as distance from the anal verge to the inferior margin of the tumor. All data were collected in a database and analyzed with SPSS statistical software (version 21 for Windows). The preoperative evaluation included history, physical examination with digital rectal examination, rigid rectoscopy, colonoscopy with biopsy and endorectal ultrasound. Patients underwent bowel preparation by enema only because we believe that an oral preparation can contaminate the operative field with liquid feces, and were given antibiotic prophylaxis.

\section{Surgical Technique}

The protocol for anesthesia was the same for all patients.

We use a standard Wolf TEM operating endoscope (Wolf \& Co., Knittlingen, Germany) with a fixed Martin stabilizing arm. The diameter of the rectoscope is $40 \mathrm{~mm}$ (the optimum limit for anal dilation). The instruments used and the principles of operative technique are those described by Buess..$^{17}$ The patient was positioned according to the location of the tumor in supine, prone, left or right lateral position. A full-thickness excision was performed in all cases of rectal cancer, with the resulting rectal wall defect left open rather than sutured. The lesions were excised intact and measured after they had been fixed to the board.

\section{Postoperative Management}

All patients were allowed sips of clear fluid starting $6 \mathrm{~h}$ after surgery. The first meal was offered after passing flatus. The pain control was administered intravenously in the operating room and was begun 30minutes prior to the end of surgery. Intravenous catheters were removed when patients could tolerate a clear fluid. Patients were discharged from the hospital when they were mobile with wellcontrolled pain, tolerated an oral diet, and resumed normal bowel functions. The patients were examined every 3 months the first year, then every 6 months the following year. Follow-up evaluation consisted of clinical examination, rigid sigmoidoscopy and endoscopic rectal ultrasound in every outpatient visit, colonoscopy one year after the resection, and computed tomography (CT) scan of the liver/abdomen at 6 months, then annually unless indicated. The site of the excision was followed up by simple search for the scar, with biopsies taken if anything abnormal was found.

\section{Results}

A total of 171patients underwent TEM between April 2004 and December 2015. The indications are presented in Table 1. Main indication of TEM was the presence of carcinoma (49,7\%). The group of patients included 97 females and 74males. The median age was 63(range 21-93)years, specimen size was 3,4(range 1-7) cm and tumor distance from the anal verge $8,5($ range $4-19) \mathrm{cm}$. Table 2 , Table 3 presents the surgical outcome of patients. Median operative time was $81,7 \mathrm{~min}$ (range 20-240) and hospital stay was of 1,4(range 1-10)days. There were 10 postoperative complications: two of three cases of postoperative bleeding had to be treated with endoscopic procedure and one with transanal procedure, two dehiscence in the intraperitoneal region required discontinuity laparoscopic resection (Hartmann) due to peritonitis in the lower abdomen, two rectovaginal fistula required reoperation (laparoscopic) with a protective stoma, one pneumothorax and one perirectal abscess one week after surgery solved with medical treatment. No patients required conversions to laparoscopic or conventional surgery. One patient with carcinoma died postoperatively of cardiopulmonary insufficiency. Definitive histology confirmed adenomas in 55cases, while in 93 malignant lesions we had 9pTis, 34 pT1, 37 pT2 and 13pT0-1 (T3 with complete response after neoadjuvant therapy following TEM). Radical surgical rescue was performed on 10patients after TEM, with no local or systemic recurrences. (Figure 1) After a median follow-up period of 58(range 3-143)months, 2(3,6\%) patients had local recurrences in the adenoma group treated by TEM, and $2(5,8 \%)$ in the T1 group, $3(8,1 \%)$ in the $\mathrm{T} 2$ group, $1(7,7 \%)$ in the $\mathrm{T} 3$ group treated by radical surgical rescue. (Table 3)

Table I Indications for TEM of this study

\begin{tabular}{|c|c|}
\hline Variables & $\mathbf{N}=\mathbf{1 7 1}$ \\
\hline \multicolumn{2}{|l|}{ Indications } \\
\hline Adenomas & 71 \\
\hline Carcinomas & 85 \\
\hline Carcinoid & 2 \\
\hline Others tumours & 5 \\
\hline Stenosis & 4 \\
\hline Rectal prolapse & 1 \\
\hline Granuloma & 1 \\
\hline Abscess & 1 \\
\hline Impacted faecaloma & 1 \\
\hline \multicolumn{2}{|l|}{ Staging of Malign Tumours(Low-Risk) } \\
\hline uT1 & 31 \\
\hline uT2 with neoadjuvant therapy & 36 \\
\hline uT3 with complete response after neoadjuvant therapy & 20 \\
\hline
\end{tabular}


Table 2 Patient and tumor characteristics of this study

\begin{tabular}{ll}
\hline Variables & $\mathbf{N}=\mathbf{1 7 1}$ \\
\hline Women : Men & $97: 74$ \\
Age(years) median(range) & $63(21-93)$ \\
Tumour size(cm) median(range) & $3,4(1-7)$ \\
Tumour distance(cm) median(range) & $8,5(4-19)$ \\
Position of the Lesion & \\
Posterior & 50 \\
Anterior & 41 \\
Left lateral & 16 \\
Right lateral & 15 \\
Two wall & 33 \\
Three wall & 10 \\
\hline
\end{tabular}

Table 3 Surgical outcomes

\begin{tabular}{ll}
\hline Variables & $\mathbf{N}=\mathbf{1 7 1}$ \\
\hline Total operative time(min) median(range) & $81,7(20-240)$ \\
Hospital stay(days) median(range) & $1,4(1-10)$ \\
Postoperative complications(\%) & $10(5,8 \%)$ \\
Bleeding & 4 \\
Dehiscence & 2 \\
Rectovaginal Fistula & 2 \\
Abscess & 1 \\
Others & 1 \\
Mortality(\%) & $1(0,5 \%)$ \\
Local recurrences & \\
Adenomas & $2(3,6 \%)$ \\
pT1 & $2(5,8 \%)$ \\
pT2 with neoadjuvant therapy & $3(8,1 \%)$ \\
pT3 with complete response after neoadjuvant & $1(7,7 \%)$ \\
therapy &
\end{tabular}

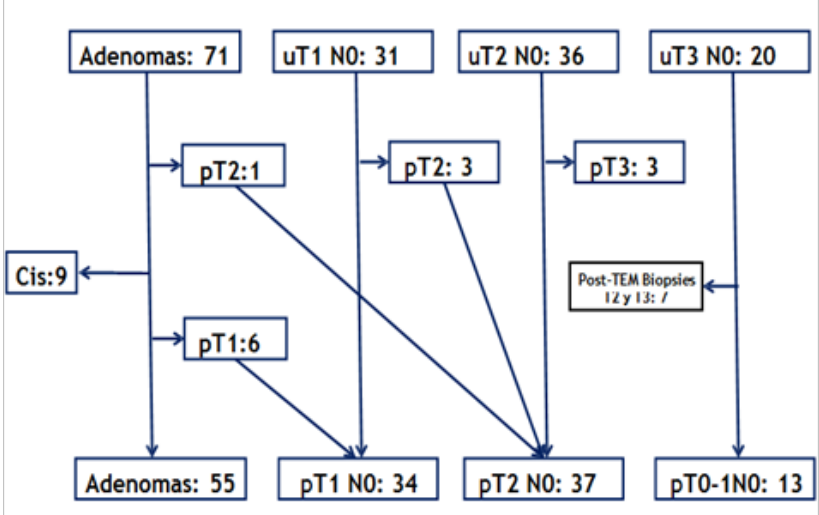

Figure I Pre-and postoperative histological diagnosis.

\section{Discussion}

TEM's availability and utilization a Caribbean medical community has been limited and remains a challenge. The National Center for Minimally Invasive Surgery has the greatest experience in endoscopic approach in Cuba. The institution's department of laparoscopic and endoscopic surgery has performed over 900 laparoscopic colorectal procedures. TEM allows greater versatility and options for the operating surgeon. The use of the operating rectoscope with a length of $20 \mathrm{~cm}$ and the four ports of access allow treating rectal and sigmoid diseases. ${ }^{5}$ TEM is used to treat a variety of disease processes, both benign and malignant. The most common uses of TEM are for resection of colonoscopically unresectable rectal adenomas (large adenomas) and selected early rectal cancers, because of its safety and low local recurrences rates. ${ }^{7,18}$ The advantage of TEM versus endoscopy is the use of both hands with a more precise dissection. The enhanced three-dimensional view of the operative field is of notable advantage. ${ }^{19}$ The main problems of TEM are restrictions on instrument manipulation and triangulation limits by using an operating rectoscope with a diameter of $4 \mathrm{~cm}$. These disadvantages include longer learning curve, longer operative time, the need for specialized instruments, and difficulty in suturing through a rigid scope. , $^{, 18,19}$ However, those disadvantages are nonexistent with the experience of the surgical team. TEM was introduced initially by Buess et al. ${ }^{20}$ for benign lesions and after that was extended to early rectal cancers. ${ }^{6,18}$ Salm et al. ${ }^{21}$ in another study about the experience with TEM in Germany, report $5,7 \%$ of radical rectal resection in patients with advanced cancer in the post-TEM histological specimen. However, when the TEM was established starting the use for T1 cancers with favorable histology including the depth of submucosal invasion and low risk of lymph node metastases. ${ }^{22-24}$ The incalculable threat after local resection is the risk of lymphatic metastasis. In low-risk pT1 tumors, lymphatic spread occurs in only $3 \%$ of patients compared to $12 \%$ in pT1 high-risk tumors, which translates into higher local recurrences in high-risk pT1 tumors treated by local excision. Our $5.8 \%$ recurrence rate for low risk $\mathrm{T} 1$ tumors compares very favorably to the literature. ${ }^{6,22,23}$ Tumors must be located at the extraperitoneal part of the rectum using the full-thickness technique. TEM is not indicated for patients with carcinomas located at the anterior wall if they are higher than $12 \mathrm{~cm}$ from the anal verge, because of a potential gas loss into the opened peritoneal cavity if the rectal wall is breached ${ }^{5}$ however Marks et al. ${ }^{25}$ reported that the high anterior location rectal lesions should be considered candidates for TEM in experienced hands. The goal of oncological surgery for rectal cancer is primarily to achieve the best cancer control and secondly to preserve function and quality of life. Local excision by TEM is controversial because of the absence of lymphadenectomy, thereby Total mesorectal excision (TME) is the best curative treatment for lower rectal cancer, with good long-term results reported after neoadjuvant radio chemotherapy. ${ }^{26}$ Nevertheless, radical surgery is associated with high rates of genitourinary and sexual dysfunction (30-40\%), anastomotic leakage (5-17\%), and changes in bowel habits (frequent bowel movements, urgency, and incomplete evacuation). Abdomino perineal resection is associated with $40 \%$ of perineal wound complications, $66 \%$ of stoma complications and patient depression in $30 \%{ }^{26-29}$

Local excision of advanced rectal cancers with curative intent remains a debatable issue. The review recommended that TEM only be used for palliative cases in T2-T3 tumors, nevertheless, researchers in several studies have described that TEM is safe and effective for patients with rectal carcinoma pT2 N0 low risk after neoadjuvant 
therapy and pT3 N0 low risk and complete response after neoadjuvant therapy who refused abdominal surgery., ${ }^{4,5,9-13,22,26,30-32}$ Our experience has shown that neoadjuvant therapy followed by TEM to treat T2-3 N0 rectal cancer is well tolerated and effective. With the standardization of the technique for the removal of tumors and the suture of rectal defects, we began to consider other possible indications in rectal and pelvic disease. These indications are known as "atypical," as they do not involve the excision of rectal adenoma or carcinoma. ${ }^{33}$ The atypical indications in our study is comparable to others reported that describes the indications in pelvic abscess, benign rectal stenosis, gastrointestinal stromal tumor, rectal prolapse, extraction of impacted fecaloma at the rectosigmoid junction and presacral tumor. ${ }^{34-38}$ In recent years, TEM via natural orifices (natural orifice transluminal endoscopic surgery: NOTES) has been used to gain access to the peritoneal cavity and to perform intraabdominal procedures. ${ }^{39-41}$ If NOTES should become a clinical reality, TEM may well play a role in its ultimate universal application. ${ }^{5,42}$ In conclusion, in an advanced Caribbean medical community, TEM can be utilized for patients' safety with good adenoma control and oncologic outcomes. Propagate of advanced surgical technologies in a developing medical remains challenging but our experience supports the feasibility and potential of this approach. Our results may be generalizable, because we used the standardized techniques and a median 58 months follow-up.

\section{Author disclosures}

Dr. Javier Ernesto Barreras González has no conflicts of interest or financial ties to disclose.

Support: Dr. Javier Ernesto Barreras González haven't corporate/ commercial relationships with any pharmaceutical or device companies that might pose a conflict of interest with this manuscript. No consultantships, honoraria, stock ownership, gifts, free or reimbursed travel/vacations, equity interests, arrangements regarding patients or other vestid interests.

\section{Acknowledgements}

None.

\section{Conflict of interest}

Dr. Javier Ernesto Barreras González hereby transfer, assign, or otherwise convey all copyright ownership, including any and all rights incidental thereto, exclusively to the Journal, in the event that such work is published by the Journal.

\section{References}

1. Buess G, Theiss R, Hutterer F, et al. Die transanal endoscopic Rectum operation. Erprobung einer neuen Methode im Tierversuch. Leber Magen Darm. 1983;13:73-77.

2. Buess G, Hutterer F, Theiss R, et al. Das System for die transanal endoscopic Rectum operation. Chirurg. 1984;55(10):677-680.

3. Kipfmuller K, Buess G, Naruhn M, et al. Training program for transanal endoscopic microsurgery. Surg Endosc. 1988;2(1):24-27.

4. Bökkerink G, De Graaf E, Punt C, et al. The CARTS study: Chemoradiation therapy for rectal cancer in the distal rectum followed by organ-sparing transanal endoscopic microsurgery. BMC Surgery. 2011;11:34.
5. Cataldo PA, Buess G. Transanal Endoscopic Microsurgery. Principles and Techniques. New York, USA: Springer; 2009.

6. Doornebosch PG, Tollenaar RA, De Graaf EJ. Is the increasing role of Transanal Endoscopic Microsurgery in curation for T1 rectal cancer justified? A systematic review. Acta Oncol. 2009;48(3):343-353.

7. Middleton PF, Sutherland LM, Maddern GJ. Transanal endoscopic microsurgery: a systematic review. Dis Colon Rectum. 2005;48(2):270284.

8. You YN, Baxter NN, Stewart A, et al. Is the increasing rate of local excision for stage I rectal cancer in the united States justified?. A nationwide cohort study from the national cancer database. Ann Surg. 2007;245(5):726-733.

9. Allaix ME, Arezzo A, Giraudo G, et al. Transanal endoscopic microsurgery vs. Laparoscopic total mesorectal excision for T2N0 rectal cancer. $J$ Gastrointest Surg. 2012;16:2280-2287.

10. Nair RM, Siegel EM, Chen DT, et al. Long-Term results of Transanal Excision after neoadjuvant chemoradiation for T2 and T3 adenocarcinomas of the rectum. J Gastrointest Surg. 2008;12(10):1797-1806.

11. Coco C, Rizzo G, Mattana C, et al. Transanal endoscopic microsurgery after neoadjuvant radiochemotherapy for locally advanced extraperitoneal rectal cancer: short-term morbidity and functional outcome. Surg Endosc. 2013;27(8):2860-2867.

12. Lezoche E, Guerrieri M, Paganini AM, et al. Transanal endoscopic versus total mesorectal laparoscopic resections of T2-N0 low rectal cancers after neoadjuvant treatment: a prospective randomized trial with a 3-years minimum follow-up period. Surg Endosc. 2005;19(6):751-756.

13. Lezoche G, Baldarelli M, Paganini AM, et al. A prospective randomized study with a 5-years minimum follow-up evaluation of transanal endoscopic microsurgery versus total laparoscopic total mesorectal excision after neoadjuvant therapy. Surg Endosc. 2008;22(2):352-358.

14. Pigalarga R, Patel NM, Rezac C. Transanal endoscopic microsurgeryassisted rectal advancement flap is a viable option for iatrogenic rectourethral fistula repair: a case report. Tech Coloproctol. 2011;15(2):209-211.

15. Martins BC, Sparapan Marques CF, Rizkallah Nahas CS, et al. A novel approach for the treatment of pelvic abscess: transrectal endoscopic drainage facilitated by transanal endoscopic microsurgery access. Surg Endosc. 2012;26:2667-2670.

16. D'Ambrosio G, Paganini AM, Guerrieri M, et al. Minimally invasive treatment of rectovaginal fistula. Surg Endosc. 2012;26(2):546-550.

17. Buess G, Kipfmuller K, Hack D, et al. Technique of transanal endoscopic microsurgery. Surg Endosc. 1988;2(2):71-75.

18. Maslekar S, Beral DL, White TJ, et al. Transanal endoscopic microsurgery: where are we now? Dig Surg. 2006;23(1-2):12-22.

19. Léonard D, Remue Ch, Kartheuser A. The Transanal Endoscopic Microsurgery procedure: standards and extended indications. Dig Dis. 2012;30(2):85-90.

20. Buess G, Mentges B, Manncke K, et al. Technique and results of transanal endoscopic microsurgery in early rectal cancer. Am J Surg. 1992;163(1):63-69.

21. Salm R, Lampe H, Bustos A, Matern U. Experience with TEM in Germany. Endosc Surg Al-lied Technol. 1994;2(5):251-254.

22. Weber GF, Rosenberg R, Murphy JE, et al. Multimodal treatment strategies for locally advanced rectal cancer. Expert Rev Anticancer Ther. 2012;12(4):481-494. 
23. Van de Velde CJH, Boelens PG, Borras JM, et al. EURECCA colorectal: Multidisciplinary management: European consensus conference colon \& rectum. European Journal of Cancer. 2014;50(1):1.e1-1.e34.

24. Kitajima K, Fujimori T, Fujii S, et al. Correlations between lymph node metastasis and depth of submucosal invasion in submucosal invasive colorectal carcinoma: a Japanese collaborative study. $J$ Gastroenterol. 2004;39(6):534-543.

25. Marks JH, Frenkel JL, Greenleaf CE, et al. Transanal endoscopic microsurgery with entrance into the peritoneal cavity: Is it safe? .Dis Colon Rectum. 2014;57910):1176-1182.

26. Allaix Me, Arezzo A, Giraudo G, et al. Transanal endoscopic microsurgery vs. Laparoscopic total mesorectal excision for T2N0 rectal cancer. gastrointest surg. 2012;16(12):2280-2287.

27. Morino M, Parini U, Allaix ME, et al. Male sexual and urinary function after laparoscopic total mesorectal excision. Surg Endosc. 2009;23(6):12331240 .

28. Wallner C, Lange MM, Bonsing BA, et al. Cooperative Clinical Investigators of the Dutch Total Mesorectal Excision Trial. Causes of fecal and urinary incontinence after total mesorectal excision for rectal cancer based on cadaveric surgery: a study from the Cooperative Clinical Investigators of the Dutch total mesorectal excision trial. J Clin Oncol. 2008;26(27):4466-4472.

29. Habr-Gama A, Perez RO. Non-operative management of rectal cancer after neoadjuvant chemoradiation. Br J Surg. 2009;96(2):125-127.

30. Borschitz T, Wachtlin D, Möhler M, et al. Neoadjuvant chemoradiation and local excision for T2-3 rectal cancer. Annals of Surgical Oncology. 2008;15(3):712-720.

31. Marks JH, Valsdottir EB, DeNittis A, et al. Transanal endoscopic microsurgery for the treatment of rectal cancer: comparison of wound complication rates with and without neoadjuvant radiation therapy. Surg Endosc. 2009;23(5):1081-1087.
32. Verseveld M, De Graaf EJR, Verhoef C, et al. Chemoradiation therapy for rectal cancer in the distal rectum followed by organ-sparing transanal endoscopic microsurgery (CARTS study). BJS. 2015;102(7):853-860.

33. Saclarides TJ. TEM/local excision: indications, techniques, outcomes, and the future. J Surg Onco. 2007;96(8):644-650.

34. Woodfield JC, Chalmers AG, Phillips N, et al. Algorithms for the surgical management of retrorectal tumours. Br J Surg. 2008;95(2):214-221.

35. Vavra P, Dostalik J, Vavrova M. Transanal endoscopic microsurgery: a novel technique for the repair of benign rectovaginal fistula. Surgeon. 2009;7(2):126-127.

36. Giaccaglia V, Stefanuto A, Cavallotti C, et al. Transanal excision of rectal pyogenic granuloma: case report and literature review. Surg Laparosc Endosc Percutan Tech. 2011;21(2):e91-92.

37. Beunis A, Pauli S, Van Cleemput M. Anastomotic leakage of a colorectal anastomosis treated by transanal endoscopic microsurgery. Acta Chir Belg. 2008;108(4):474-476.

38. Serra-Aracil X, Mora-Lopez L, Alcantara-Moral M, et al. Atypical indications for transanal endoscopic microsurgery to avoid major surgery. Tech Coloproctol. 2014;18(2):157-164.

39. Trunzo JA, Delaney CP. Natural orifice proctectomy using a transanal endoscopic microsurgical technique in a porcine model. Surg Innov. 2010;17(1):48-52.

40. Sylla P. Current experience and future directions of completely NOTES colorectal resection. World J Gastrointest Surg. 2010;2(6):193-198.

41. Sylla P, Rattner DW, Delgado S, et al. NOTES transanal rectal cancer resection using transanal endoscopic microsurgery and laparoscopic assistance. Surg Endosc. 2010;24(5):1205-1210.

42. Marks JH. TEM as a Platform for NOTES. J Gastrointest Surg. 2011;15(8):1313-1315. 